\title{
Effect of Carbon-coated Silicon/Graphite Composite Anode on the Electrochemical Properties
}

\author{
Hyung Sun Kim, Kyung Yoon Chung, and Byung Won Cho \\ Battery Research Center; Korea Institute of Science and Technology (KIST), P.O. Box 131, Cheongryang, Seoul 130-650, Korea \\ ${ }^{*}$ E-mail: kimhs@kistrekr \\ Received December 13, 2007
}

\begin{abstract}
The effects of carbon-coated silicon/graphite (Si/Gr.) composite anode on the electrochemical properties were investigated. The nanosized silicon particle shows a good cycling performance with a reasonable value of the first reversible capacity as conpared with microsized silicon particle. The carbon-coated silicon/graphite composite powders have been prepared by pyrolysis method under argon $/ 10 \mathrm{wt} \%$ propylene gas flow at 700 ${ }^{0} \mathrm{C}$ for $7 \mathrm{~h}$. Transmission electron microscopy (TEM) analysis indicates that the carbon layer thickness of $5 \mathrm{~nm}$ was coated unifomly onto the surface silicon powder. It is confinmed that the insertion of lithiun ions change the crystalline silicon phase into the amorphous phase by X-ray diffraction (XRD) analysis. The carbon-coated composite silicon/graphite anode shows excellent cycling performance with a reversible value of $700 \mathrm{mAh} / \mathrm{g}$. The superior electrochenical characteristics are attributed to the enlianced electronic conductivity and low volume change of silicon powder during cycling by carbon coating.
\end{abstract}

Key Words : Nanosized Si, Carbon coating, Lithium ion battery, Composite anode

\section{Introduction}

In recent years, alternative anode materials have been investigated in lithium ion batteries. Silicon-based materials such as $\mathrm{SiO}, \mathrm{SiO}_{2}$ and metallic $\mathrm{Si}$ have been proposed as anodes to replace the lithium metal and carbonaceous materials. ${ }^{1+4}$ Silicon can reversibly accommodate lithium by forming $\mathrm{Li}_{4.4} \mathrm{Si}$ alloys, corresponding to a theoretical specific capacity of $4,200 \mathrm{mAh} / \mathrm{g} .6 \%$ Also, it is very suitable for anode material because the potential of lithium insertion into silicon is below $0.5 \mathrm{~V} v \mathrm{v}$. $\mathrm{Li} / \mathrm{Li}^{+}$. However, lithium/silicon alloys usually exhibit rapid capacity fading during cycling. ${ }^{84}$ This is mainly attributed to the large volume change up to three times between lithium insertion and de-insertion reaction, which leads to physical stress and poor cyclability. Another factor for poor cycling performance is due to the low electrical conductivity of silicon materials. Many attempts, therefore, have been focused on overcoming these problems with various techniques . ${ }^{10-12}$

It has been reported that silicon and graphite-based composite synthesized by thermal pyrolysis of polymer dispersed with nanosized silicon and fine graphite particle shows a reversible capacity of $700 \mathrm{mAl} / \mathrm{g}$ with better cyclability than nanocrystalline silicon alone. ${ }^{13}$ In this case, graphite phase plays an important role for improving the cycling performance of the $\mathrm{Si} / \mathrm{C}$ composite, serving as a media that prevents active particle-particle interaction. ${ }^{11}$ In this work, in order to improve the cycling performance and volume change of silicon electrode, we have synthesized new carbon-coated silicon and graphite composite anode by hydrocarbon gas decomposition and investigated its effect on the electrochemical properties.

\section{Experimental}

Commercial microsized natural graphite and nanosized silicon powder (diameter: $60 \mathrm{~nm}$, Alfa Aesar, 98\%) at a weight ratio $9: 1$ was used as starting materials. These powders were mixed in a plastic bottle at $300 \mathrm{rpm}$ for $1 \mathrm{~h}$ by rotator. Then, they were placed in a tubular fiumace and thermally decomposed at $700^{\circ} \mathrm{C}$ for $7 \mathrm{~h}$ under $\mathrm{Ar}+10 \mathrm{wt} \%$ propylene gas to prevent oxidation and form carbon phase on the powders. Examination of the morphology of the powder was conducted by transmission electron microscopy (Tecnai G2, FEI Hong Kong Co., Ltd.). The crystallography structure of the electrodes was analyzed by X-ray diffraction (Rint/Dmax-2500, Rigaku) with CuK $\alpha$ radiation. To examine the electrochemical characteristics, the obtained powders were mixed with poly(vinylidene fluoride) binder (5 wt \%), acetylene black conductive material ( $5 \mathrm{wt} \%$ ) and $\mathrm{N}$ methyl pyrrolidinone organic solvent at high speed mixer. The viscous slurry was cast on to copper foil currentcollector by the doctor blade technique and dried at $80^{\circ} \mathrm{C}$ under vacuum for $24 \mathrm{~h}$. The resulting electrode was used as a working electrode in a cell with a lithium metal counter electrode and the electrolyte was $1 \mathrm{M} \mathrm{LiPF}_{6}$ in a mixture of ethylene carbonate, dimethyl carbonate and ethyl-methyl carbonate $(1: 1: 1)$ by volume ratio. The separator was a Celgard 2400 microporous polypropylene membrane. All cells (dimension: $3 \times 4 \mathrm{~cm}$ ) were enveloped in aluminum plastic pouches and sealed under vacuum in a dry room (dew point; $-50{ }^{\circ} \mathrm{C}$ ). The impedance spectra of the assembled cells were recorded by impedance gain phase analyzer (Solartron SI 1260) coupled with electrochemical interface (Solartron SI 1286). The cells were cycled using galvano- 
static method in the potential range of 0.005 and $1.0 \mathrm{~V}$ vs. $\mathrm{Li} / \mathrm{Li}^{+}$using a Maccor battery cycler (S 4000 . USA).

\section{Results and Discussion}

Figure 1 shows the first voltage profiles of $\mathrm{Li} / \mathrm{Si}$ half cell containing different silicon particle size. The specific discharge capacity of nanosized silicon powder $(60 \mathrm{~nm})$ is about $3,000 \mathrm{mAh} / \mathrm{g}$. This value corresponds to two times larger than that of microsized silicon powder $(45 \mu \mathrm{m})$. In addition. the coulombic efficiency of the former is also much better than that of the latter. Theses indicate that a decrease in the particle size can enhance lithium-insertion capacity as well as charge-discharge reaction kinetics. It was reported that the finer powder is favorable for kinetics due to its larger specific surface area and shorter lithium-diffusion length in the particles. ${ }^{15}$ However, the voltage polarization of the electrodes shows a similar pattern irrespective of particle size. In order to coat carbon on to the nanosized silicon particles, they were placed in a tubular furnace and thermally decomposed at $700{ }^{\circ} \mathrm{C}$ for $7 \mathrm{~h}$ under $\mathrm{Ar}+10 \mathrm{wt} \%$ propylene gas. Figure 2 shows TEM image of carbon-coated silicon powder. The outer surface of the nanosized silicon powder was covered with an amorphous carbon layer of 5

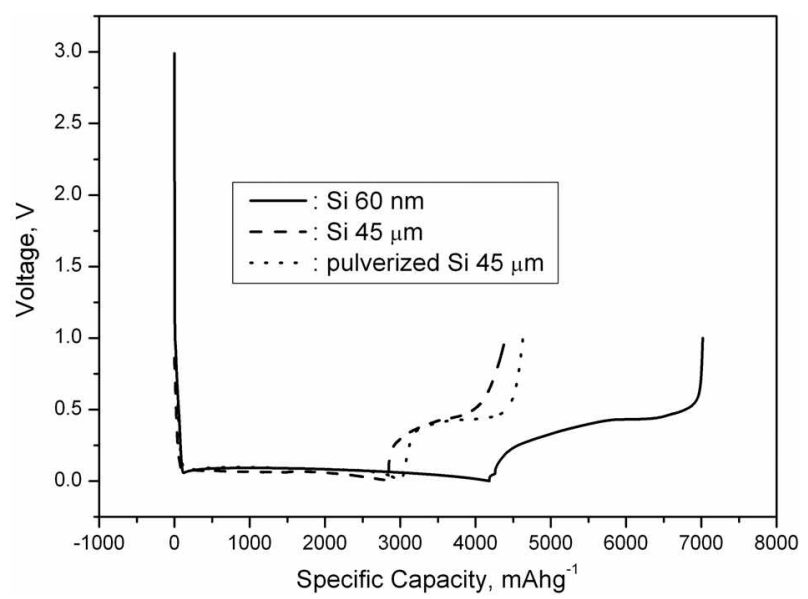

Figure 1. Voltage profiles of silicon anodes during the first cycle (current density: $0.25 \mathrm{mAcm}^{-3}$ ).

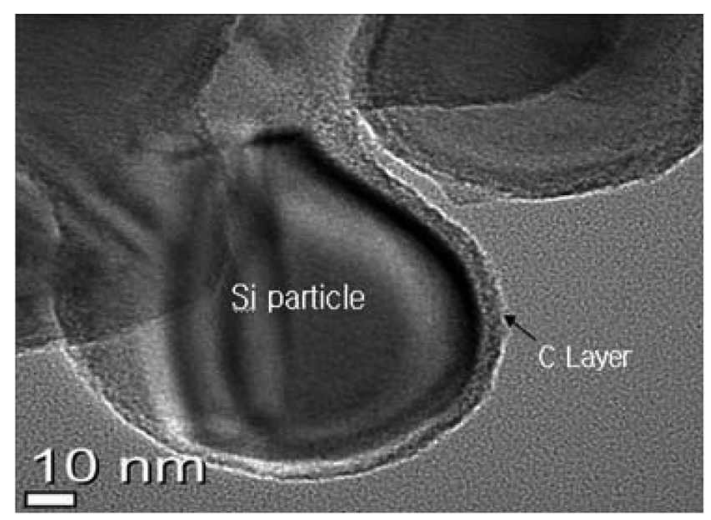

Figure 2. TEM image of C-coated $S_{1}$ powder.

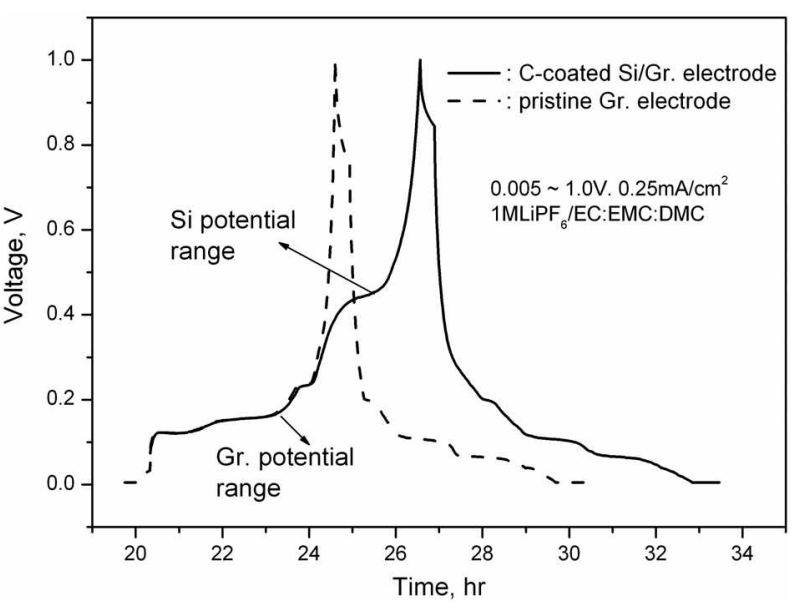

Figure 3. Charge/Discharge curves of $\mathrm{C}$-coated $\mathrm{Si} / \mathrm{Gr}$. anode and Gr. anode.

$\mathrm{nm}$ thickness. This supports the generally accepted the tipgrowth mechanism of carbon materials. ${ }^{16}$ The hydrocarbon gas first decomposes on the active material particles and finally the carbon layer forms on the surface of the silicon particle. The composite silicon/graphite anode obtained by carbon coating ( $\mathrm{C}$-coated $\mathrm{Si} / \mathrm{Gr}$.) decreased contact surface area between electrode and electrolyte. Therefore, this composite anode can be maintained its mechanical stability by relieving stresses resulting from silicon volume change. Figure 3 shows the voltage profiles of $\mathrm{C}$-coated $\mathrm{Si} / \mathrm{Gr}$. composite anode and $\mathrm{Gr}$. anode at the $2^{\text {nti }}$ cycle. In the charge process, the lithium de-insertion behavior is characterized by silicon electrode with plateau potential regions around 0.45 and $0.5 \mathrm{~V} v$ s. $\mathrm{Li} / \mathrm{Li}^{+}$, meanwhile such a plateau potential was not detected in the lithium insertion process. It has been reported that crystalline silicon discharged to $0 \mathrm{~V} v s . \mathrm{Li}^{2} \mathrm{Li}^{-}$ has a obvious above plateau during charge, while no plateau was detected when the cell was discharged to $0.05 \mathrm{~V}$ is. $\mathrm{Li} /$ $\mathrm{Li}^{-17}{ }^{17}$ Cycling silicon anodes below $0.05 \mathrm{~V} v$ s. $\mathrm{Li}^{2} \mathrm{Li}^{+}$results in the formation of new crystalline phase from amorphous phase during lithium insertion process. This $\mathrm{Li}_{15} \mathrm{~S}_{14}$ crystalline phase then converts back to amorphous $\mathrm{LixSi}$ in the potential range of 0.45 and $0.5 \mathrm{~V}$ vs. $\mathrm{Li}^{2} / \mathrm{Li}^{-}$during the lithium de-insertion process. ${ }^{18}$ Figure $4(\mathrm{~A})$ and $4(\mathrm{~B})$ shows that the impedance spectrum results of pristine $\mathrm{Si} / \mathrm{Gr}$. and $\mathrm{C}$ coated $\mathrm{Si} / \mathrm{Gr}$. half cell before and after $5^{\text {th }}$ cycle test, respectively. Impedance spectroscopy measurements were performed over a frequency range from $1 \mathrm{MHz}$ to $0.1 \mathrm{~Hz}$. The ac amplitude used during the measurement was $10 \mathrm{mV}$. As shown in Figure 4(A), it shows almost similar interfacial resistance values of $\sim 1,000 \Omega$ before cycle test irrespective of carbon coating. However, it was observed considerable difference between Figure $4(\mathrm{~A})$ and $4(\mathrm{~B})$ after cycle test When $\mathrm{C}$-coated $\mathrm{Si} / \mathrm{Gr}$. composite anode is compared with pristine $\mathrm{Si} / \mathrm{Gr}$. anode, the first semi-circle at high frequency increased after $5^{\text {th }}$ cycle test in the case of pristine $\mathrm{Si} / \mathrm{Gr}$. anode relative to $\mathrm{C}$-coated $\mathrm{Si} / \mathrm{Gr}$. anode. This semi-circle represents the inter-particle contact resistance such as silicon/carbon or carbon/carbon contacts. ${ }^{19}$ Therefore, the 

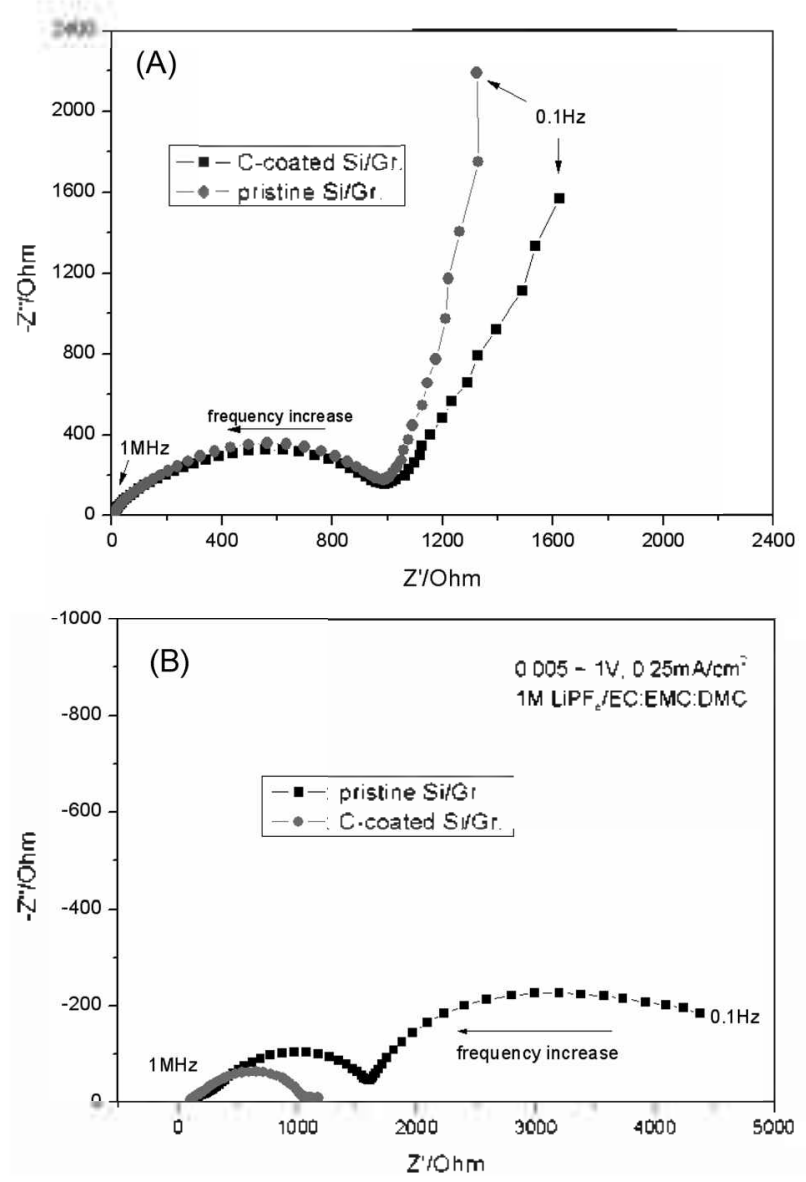

Figure 4. AC impedance spectrum of Li/Si cells before cycle test (A) and after $5^{\text {lh }}$ cycle test (B).

reduction in the diameter of the semi-circle may be attributed to the decreased contact resistance by carbon coating. The second semi-circles at low frequency also increased significantly after cycle test. This phenomenon can be ascribed to a growth of a passive layer thickness due to the reactivity of pristine silicon electrode and the electrolyte. Figure 5 shows the voltage profiles of pristine $\mathrm{Si} / \mathrm{Gr}$. and Ccoated $\mathrm{Si} / \mathrm{Gr}$. anode for the first and $5^{\text {th }}$ cycle, respectively. C-coated Si/Gr. anode showed better cycling performance than pristine $\mathrm{Si} / \mathrm{Gr}$. anode. It is interesting to notice that $\mathrm{C}$ coated $\mathrm{Si} / \mathrm{Gr}$. anode provides the plateau potential $(0.45 \mathrm{~V}$ $\left.v s . \mathrm{Li}^{2} \mathrm{Li}^{-}\right)$in the charge process even after cycling. whereas pristine $\mathrm{Si} / \mathrm{Gr}$. anode shows a little plateau potential at the first cycle and disappears after $5^{\text {th }}$ cycle test. When lithium ions are inserted into amorphous silicon. sloping voltage profiles are observed during the cycling. ${ }^{20} \mathrm{C}$-coated $\mathrm{Si} / \mathrm{Gr}$. composite anode has the similar voltage curve patterns showing good lithium insertion/de-insertion reversibility for the first five cycles. This effect may be attributed to the increased mechanical stability by carbon coating treatment. Figure 6 shows the cycling performance of C-coated Si/Gr. anode and pristine $\mathrm{Si} / \mathrm{Gr}$. anode at a current density of 0.25 $\mathrm{mA} / \mathrm{cm}^{2}$. These electrodes consisted of $10 \mathrm{wt} \% \mathrm{Si}$ and 90 $w \mathrm{t} \%$ natural graphite active material. Although the initial discharge capacity of $750 \mathrm{mAh} / \mathrm{g}$ can be obtained for the two

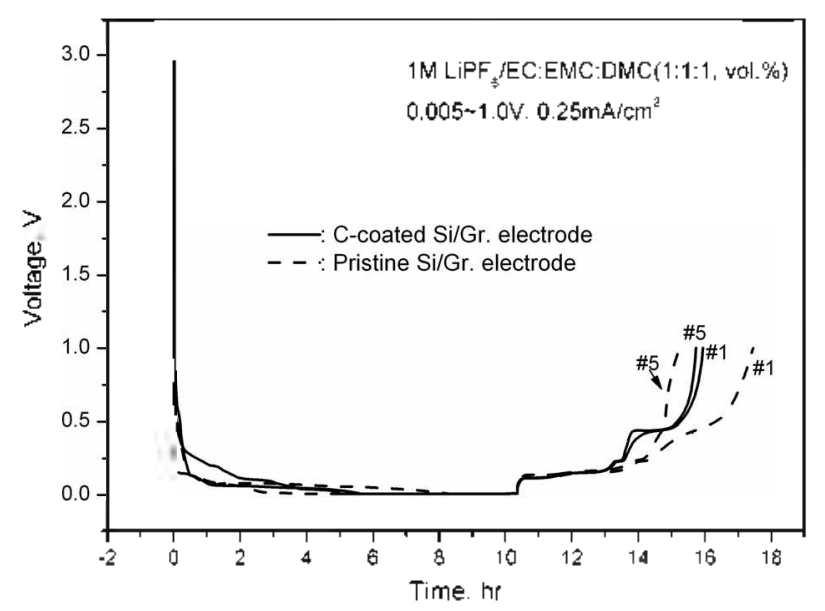

Figure 5. Charge Discharge curves of $\mathrm{C}$-coated $\mathrm{Si} / \mathrm{Gr}$ anode and pristine $\mathrm{Si} / \mathrm{Gr}$. anode.

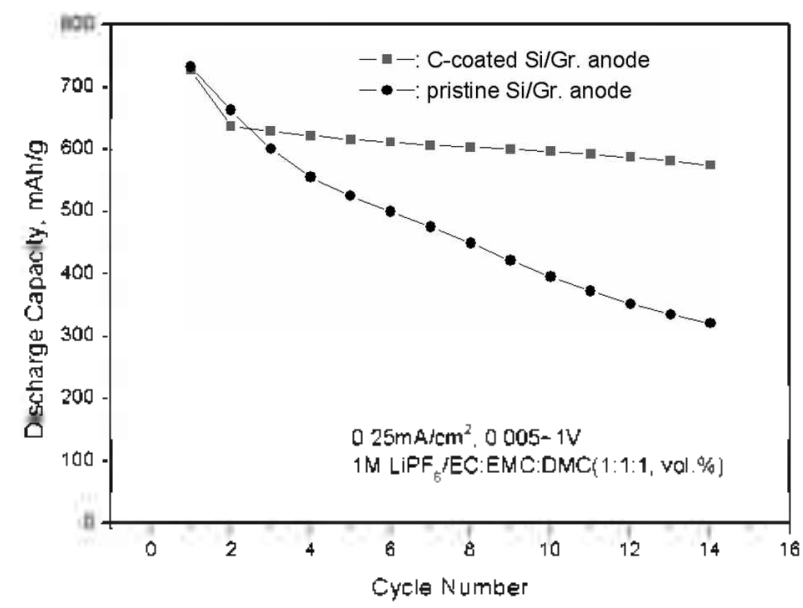

Figure 6. Cycling performance of $\mathrm{C}$-coated $\mathrm{Si} / \mathrm{Gr}$. anode and pristine SiGr. anode.

anodes, C-coated $\mathrm{Si} / \mathrm{Gr}$. composite anode shows better cycling performance compared with pristine $\mathrm{Si} / \mathrm{Gr}$. anode. In view of discharge capacity amount, carbon had no electrochemical activity towards lithium insertion in the potential range of $0.005-1 \mathrm{~V} v s . \mathrm{Li} / \mathrm{Li}^{-}$. But carbon layer plays a very important role to increase conductivity of silicon and serves as a buffering matrix for the formation of $\mathrm{Li}_{\mathrm{K}} \mathrm{Si}$. Figure 7 shows cyclic efficiency of $\mathrm{C}$-coated $\mathrm{Si} / \mathrm{Gr}$. anode and pristine $\mathrm{Si} / \mathrm{Gr}$. anode, respectively. As we expected, C-coated $\mathrm{Si} / \mathrm{Gr}$. electrode shows around $100 \%$ cyclic efficiency for the cycling test except the first cycle. The irreversible capacity is probably due to the electrolyte decomposition and solid electrolyte interface formation on the surface electrode during the first lithium insertion. As shown in Figure 7, the first cyclic efficiency of $\mathrm{C}$-coated $\mathrm{Si} / \mathrm{Gr}$. electrode is $88 \%$, which is a slightly better than that of pristine $\mathrm{Si} / \mathrm{Gr}$. electrode. This small increase in the cyclic efficiency may be attributed the presence of carbon layer formed in the active material, which reduce the side reactions since carbon has less surface area compared with pristine silicon powder. Figure 8 shows XRD patterns of $\mathrm{C}$-coated $\mathrm{Si} / \mathrm{Gr}$. anode 


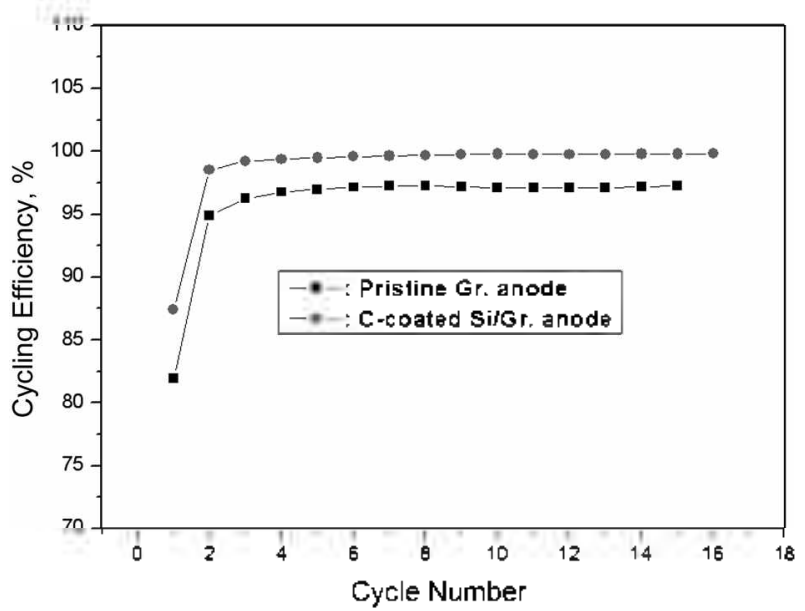

Figure 7. Cyclic efficiency of of C-coated SiGr. anode and pristine $\mathrm{Si} / \mathrm{Gr}$. anode.

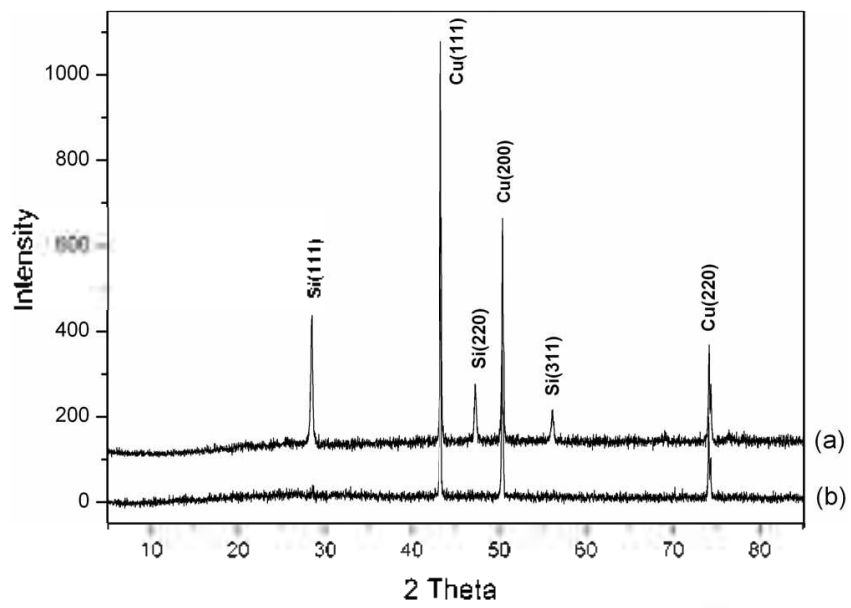

Figure 8. XRD pattems of $\mathrm{C}$-coated $\mathrm{Si} \mathrm{Gr}$. anode (a) before and (b) after cycle test.

before and after the $15^{\text {th }}$ cycle, respectively. The XRD peaks related to silicon can not be detected after cycle test. It means that the insertion of lithium ions gradually destroys the crystal structure of silicon, which leads to the formation of a metastable amorphous Li-Si alloy. These alloys are not long-range ordered structures. The low diffision rate of lithium in the Li-Sn alloys restrains the formation of the long-range ordered structure. ${ }^{21}$ It is reasonable to assume that the insertion of lithium ions destroys the bonds among silicon atoms. As a result, silicon atoms bond with a large amount of lithium ions and may be surrounded by several lithium atoms, especially at the deep discharge level. Thus, the ordered sites of silicon atoms in the lattice are disturbed and the crystal structure of silicon is destroyed. It is also understandable that lithium ions inserted in silicon can not move reversibly to form the ordered $\mathrm{Li}-\mathrm{Si}$ alloy. The remaining lithium ions can not be completely extracted from nanosized silicon by electrochemical method and act as the main resource of irreversible capacity loss. ${ }^{22}$ This is one of the main factors for the capacity fading during cycling.

\section{Conclusion}

A carbon-coated silicon/graphite powders were synthesized by pyrolysis under argon $/ 10 \mathrm{wt} \%$ propylene gas flow. After themal treatment, the amorphous carbon layer thickness of $5 \mathrm{~nm}$ was coated uniformly onto the surface silicon powder. Although the electrochemical insertion of lithium ion changes the crystal structure of silicon into the amorphous state, this electrode shows a high reversible capacity over $600 \mathrm{mAh} / \mathrm{g}$ for the first 15 cycles. Also, it is found that reducing silicon powder size shows a good cyclability and a high reversible capacity. Therefore, carbon coated nanosized silicon composite electrodes expected to be promising alternative anode for commercial lithium ion batteries.

Acknowledgments. This research supported by 2008 Core Technology Development Project of the Ministry of Commerce, Industry and Energy (MOCIE).

\section{References}

1. Winter, M:- Besenlhard, J. O. Electrochim Acta 1991, 4.5, 31.

2. Huggins, R. A. Solid State Ionics 1998, 113, 57.

3. Li, H.; Huang, X.; Chen, L.; Wu, Z.; Liang, Y. Electrochem. Solid State Lett. $1999,2,547$

4. Doh, C. H.; Kim, S. I.; Jeong, K. Y.; Jin, B. S.; An, H. K.; Min, B. C.; Moon, S. I.; Yun, M. S. Bull. Korem Chem. Soc. 2006, 27, 1175 .

5. Wen, C. J.; Huggins, R. A. I. Solid State Chem. 1996, 37, 271.

6. Amezawa, K.; Yamamoto, N.; Tomii, Y.; Ito, Y. J. Electrochen. Soc. $1998,145,986$.

7. Anami, A.; Huggins, R. A. J. Pouer Soures 1992, $38,351$.

8. Weydanz, W. J; Wolhlfahrt-Mehrens, M.; Huggins, R. A. $J$. Poner Soliress 1999, 81-82, 237.

9. Lee, H. Y.; Lee, S. M. Electrochenistr: Communications 2004, 6 , 465 .

10. Dimov, N.; Kugino, S.; Yoshio, M. J. Power Solmess 2004, 136, 108.

11. Idota, Y.; Kubota, T.; Matsutuji, A.; Maekawa, Y.; Miyasaka, T. Science 1997, 276, 1395

12. Dimov, N.; Kugino, S.; Yoshio, M. Electrochim. Acta 2003, 48 , 1579 .

13. Yang, J.; Wang, B. F.; Liu, Y,; Xie, J. Y.; Wen, Z. S. Electrochem. Solid-State Lett. 2003, 6, Al54.

14. Dimov, N.; Fukuda, K.; Lmeno, T.; Kugino, S.; Yoshio, M. $J$. Power Sontres 2003, 114,88.

15. Liu, W.; Guo, Z.; Young, W.; Slieh, D.; Wu, H.; Yang, M.; Wu, N J. Power Sontres 2005, 140, 139

16. Zhang, Z.; Dewan, C.; Kothari, S.; Mitra, S.; Teeterg, D Materials Science and Engineering $B$ 2005, 116,363 .

17. Obrovac, M. N.; Christensen, L. Electrochemical and Solid-State Lett. 2004, 7, A93.

18. Hatchard, T. D.; Dahn, J. R. J. Electrochem. Soc. 2004, 151, A838.

19. Guo, Z. P.; Wang, J. Z.; Liu, H. K.; Dou, S. X. J. Power Sources $2005,146,448$

20. Kim, J.; Kim, $\mathrm{H}$; Sohn, H. Electrochemistr? Commmications $2005,7,557$.

21. Courtney, I. A.; Dahn, J. R I. Electrochem. Soc. 1996, 144, 2045.

22. Li, H.; Huang, X.; Chen, L.; Zhou, G; Zhang, Z.; Yu, D.; Mo, Y.; Pei, N. Solid State Ionics 2000, 135, 181 . 